\title{
Inclusive Lectures: How Often Do We See Them Across Anatomy and Medical Education?
}

\author{
Eleni Patera ${ }^{1}[$ ]
}

Accepted: 19 September 2021 / Published online: 23 September 2021

(c) Crown 2021

\section{Dear Editor,}

The association between medical students' learning styles and views on the value of attending lectures has been recently investigated by Mokahal et al. [1]. While the authors thoroughly investigated how students' learning styles affect their views on the value of lectures, they did not receive any student feedback on how well designed and structured the lectures' content has been and whether that had a negative impact on students' motivation to attend lectures. In the recent years, it has been observed that anatomy and medical educators are individuals who come from diverse academic backgrounds and do not necessarily hold a degree in medical education. Hence, that raises questions in terms of the extent that anatomy and medical educators are aware of the various learning theories that fall under the broad chapter of medical education such as the cognitive load theory, and how these should be integrated in their daily practice. From my personal experience as an alumna and anatomy educator as well, there have been several times that I either received or observed a lecture that contained an enormous amount of written information in a single PowerPoint slide. If PowerPoint slides or student worksheets are not designed effectively, this can result in an extraneous load for students, therefore having a negative impact on their cognitive load [2]. Additionally, I have also observed that a great amount of PowerPoint presentations and lecture handouts are usually not inclusive, meaning that they often have a white background and black text on it that is often too dazzling and too small to read, therefore making it difficult for individuals with dyslexia to read it. According to the British Dyslexia Association it is preferred for individuals who prepare PowerPoint presentations to use a dyslexia friendly style guide part of it which includes using single-color backgrounds such as

Eleni Patera

elpa9530@colorado.edu

1 Department of Anatomy, School of Biomedical Sciences, College of Medical and Dental Sciences, Institute of Clinical Sciences, University of Birmingham, Birmingham, UK

a cream color, a readable font style such as Arial, and font size of around 12-14 [3, 4]. Additionally, by avoiding using green and red colors that makes slides accessible to individuals who have green-red color blindness [3, 4]. While some may argue that green and red colors are very frequently used to illustrate lymph nodes and arteries, respectively, it is important for anatomy and medical educators to use these two colors only when it is deemed necessary. Overall, it is the educator's responsibility to ensure that their teaching material is as inclusive and accessible as it could be.

\section{Declarations}

Ethical Approval NA.

Informed Consent NA.

Conflict of Interest The author declares no competing interests.

\section{References}

1. Mokahal AE, Ahmad A, Habib JR, Nasrallah AA, Francis G, Sabra R, Zgheib NK. Do medical students' learning styles and approaches explain their views and behavior regarding lecture attendance?. Med Sci Educ. 2021. https://doi.org/10.1007/s40670-021-01362-3.

2. Van Merriënboer JJ, Sweller J. Cognitive load theory in health professional education: design principles and strategies. Med Educ. 2010;44:85-93.

3. British Dyslexia Association. Dyslexia style guide 2018: creating dyslexia friendly content. 2018. https://cdn.bdadyslexia.org.uk/ uploads/documents/Advice/style-guide/Dyslexia_Style_Guide_ 2018-final-1.pdf?mtime $=20190409173950 \&$ focal $=$ none. Accessed 20 Aug 2021.

4. University of Sheffield. Creating accessible PowerPoint presentations. University of Sheffield. 2021. https://www.sheffield.ac.uk/ apse/digital/digital-accessibility/powerpoint. Accessed 20 Aug 2021.

Publisher's Note Springer Nature remains neutral with regard to jurisdictional claims in published maps and institutional affiliations. 